\title{
Magnitude of prelacteal feeding practice and its association with place of birth in Ethiopia: a systematic review and meta- analysis, 2017
}

Wubet Worku Takele ${ }^{1 *}$, Amare Tariku $^{2}$, Fasil Wagnew ${ }^{3}$, Daniale Tekelia Ekubagewargies ${ }^{4}$, Wondale Getinet ${ }^{5}$, ${\text { Lema } \text { Derseh }^{6} \text { and Degefaye Zelalem Anlay }}^{1}$

\begin{abstract}
Background: Prelacteal feeding is one of the commonest inappropriate child feeding practice which exposes to malnutrition, infection, and neonatal mortality. However, there is no systematic review and meta-analysis that estimates the pooled prevalence of prelacteal feeding and its association with place of birth in Ethiopia. Therefore, this study aimed at investigating the magnitude of prelacteal feeding practice and its association with home delivery in the country.

Methods: Primary studies were accessed through, HINARI and PubMed databases. Additionally, electronics search engines such as Google Scholar, and Google were used. The Joana Briggs Institute quality appraisal checklist was used to appraise the quality of studies. Data were extracted using Microsoft Excel spreadsheet. Heterogeneity between the studies was examined using the $\mathrm{I}^{2}$ heterogeneity test. The DerSimonian and Liard random-effect model was used. The random effects were pooled after conducting subgroup and sensitivity analyses. Publication bias was also checked.

Results: A total of 780 primary studies were accessed. However, about 24 studies were included in the qualitative description and quantitative analysis of the prevalence of prelacteal feeding. To examine the association between home delivery and prelacteal feeding practice, only six studies were included. The prevalence of prelacteal feeding ranged from 6.1-75.8\%. The pooled prevalence of prelacteal feeding among Ethiopian children was 26.95\% (95\% Cl: $17.76 \%, 36.14 \%)$. The highest prevalence was observed in the Afar region. The pooled odds of prelacteal feeding among women who gave birth at home was increased by 5.16 ( $95 \% \mathrm{Cl}: 3.7,7.2)$ folds as compared to those who gave birth at Health institutions.

Conclusion: Prelacteal feeding practice in Ethiopia was found to be high. Home delivery was strongly associated with prelacteal feeding practice. Therefore, promoting institutional delivery and strengthening of the existing child nutrition strategies are recommended.
\end{abstract}

Keywords: Ethiopia, Place of birth, Prelacteal feeding, Systematic review and meta-analysis

\footnotetext{
* Correspondence: wubetakele380@gmail.com

'Department of Community Health Nursing, School of Nursing, College of

Medicine and Health Sciences, University of Gondar, Gondar, Ethiopia

Full list of author information is available at the end of the article
}

(c) The Author(s). 2018 Open Access This article is distributed under the terms of the Creative Commons Attribution 4.0 International License (http://creativecommons.org/licenses/by/4.0/), which permits unrestricted use, distribution, and reproduction in any medium, provided you give appropriate credit to the original author(s) and the source, provide a link to the Creative Commons license, and indicate if changes were made. The Creative Commons Public Domain Dedication waiver (http://creativecommons.org/publicdomain/zero/1.0/) applies to the data made available in this article, unless otherwise stated. 


\section{Background}

Exclusive breastfeeding (EBF) is one of the core indicators of Infant and Young Child Feeding(IYCF) practices providing many health benefits for the mother, as well as for her growing baby [1]. It reduces unnecessary expenses following health care service costs and infant feeding [2]. The World Health Organization (WHO) recommends exclusive breastfeeding for the first 6 months of age [3]. However, malpractices like prelacteal feeding is a bottleneck in ensuring optimal breastfeeding [4]. Prelacteal feeding is defined as the administration of any solid, semisolid, or liquid food other than breast milk to an infant during the first 3 days of birth [5]. The commonest foods given by Ethiopian women are butter, plain water, cow milk, sugar with water, and formula milk [6-8].

Prelacteal feeding might result in receiving insufficient breast milk, lactation failure, diarrhea, shortening of the breastfeeding duration, insufficient weight gain, and increased susceptibility to infection [9]. In addition, it is associated with late initiation of breastfeeding [10-12], which in turn leads to early neonatal morbidity and mortality [12-14]. Chronic and acute forms of under-nutrition are also the lethal effects of prelacteal feeding [15]. Gradually, early nutritional deficits are linked to impairments in intellectual performance, poor work capacity, and adverse reproductive outcomes [16]. Global risk assessment of suboptimal breastfeeding indicates that about $96 \%$ of all infant deaths in developing countries are attributable to inappropriate feeding occurring during the first 6 months of life [17]. Inappropriate breastfeeding including prelacteal feeding is responsible for around $45 \%$ of neonatal infection, $30 \%$ of diarrheal, and $18 \%$ of acute respiratory deaths in children aged below 5 years [18]. Furthermore, a recent study has proved that prelacteal feeding increases the risks of developing chronic noncommunicable diseases, diabetes mellitus, obesity, autoimmune disorders, and cardiovascular diseases in later ages [9].

Studies in different parts of the world reported that prelacteal feeding is a prevailing problem. For instance, it is reported to be about $73.3 \%$ in Vietnam [5], nearly a third (32.2\%) in sub-Saharan Africa [19], 60\% in Egypt [20], 31.3\% in Uganda [21]. In Ethiopia, it ranged from $6.7-58.8 \%$ in different parts of the country [7, 22-25].

Cesarean section delivery and milk insufficiency were among perceived myths for prelacteal feeding [26]. An increased likelihood of prelacteal feeding was observed among mothers who had a lower educational level [27], attended fewer antenatal care visits, multiple births, delivering male infant as well as delivering the small sized baby [6]. Moreover, studies conducted in Ethiopia indicated that home delivery has a positive association with prelacteal feeding [28-30].
In cognizance of the severity as well as the wide spreading practices of inappropriate breastfeeding, Ethiopia has been devising different strategies including generating of health extension program, and working in collaboration with Non-Governmental Organizations (NGOs) [31, 32] in the areas of IYCF.

Despite various studies conducted in different parts of the country, the pooled national prevalence of prelacteal feeding is unknown. Likewise, results of the effect of home delivery on prelacteal feeding practice have been reported inconclusively. Therefore, the aim of this systematic review and meta-analysis was to determine the pooled national prevalence of prelacteal feeding and its association with home delivery. The findings of this study could help in improving the current IYCF (exclusive breastfeeding) practices in the country.

\section{Methods}

\section{Study setting}

This systematic review and meta-analysis were conducted in Ethiopian setting. Ethiopia is one of Africa's populous nation having nearly 100,000,000 people with an area of $1,100,000 \mathrm{~km}^{2}$ making it the 27th largest country in the world. The country has diversified religion and cultures. In the country, traditional malpractices related to child feeding are critical problems affecting lots of children and women health. The country is working jointly with international partners to reduce maternal and child under-nutrition through the launching of IYCF, and National Nutrition Program (NNP). Likewise, reducing inappropriate child feeding and other maladaptive practices are amongst the health packages in which the country is working on. According to the 2016 Ethiopian Demographic and Health Survey (EDHS) report, the coverage of institutional delivery is reported to be $26 \%$ [33].

\section{Search strategies and quality appraisal}

Articles were accessed through an electronics search of international databases, including, PubMed, Science direct, and HINARI. Similarly, Google Scholar and Google were used to retrieve extra articles including grey literature. Articles were searched and accessed by two reviewers (WWT, and DTE) using the following key terms, "prelacteal feeding practice", "prevalence", "associated factors", "determinant factors", "predictors", "timely initiation of breastfeeding" "mothers", and "Ethiopia". These all key terms were searched by a combination of Boolean operators of "AND", and "OR" as appropriate. Furthermore, additional articles were retrieved by cross referencing. For those studies having similar outcome of interest with the current objectives, their abstracts and the full-text were thoroughly reviewed. The quality of each article was appraised by three independent reviewers (WWT, AT, and FWS) using the Joana Brigg's 
Institute (JBI) critical appraisal checklist for simple prevalence [34] and analytical cross-sectional studies [35] having nine and eight checklist items, respectively. Interpersonal scoring discrepancies during critical appraisal were resolved after a thorough discussion by reviewing the articles together. In case of persistent arguments during the quality assessment process, the mean scores of the three reviewers' were calculated. All articles scored greater than $50 \%$. This study was prepared by strictly following the standardized scientific writing format of the Preferred Reporting Items for Systematic Reviews and Meta-Analyses (PRISMA) guidelines having twenty-seven checklist items [36].

\section{Eligibility criteria \\ Inclusion criteria}

Studies which described the prevalence of prelacteal feeding and risk factor (home delivery) were included.

There was no design, publication status, or language restrictions in this review as long as it was conducted in Ethiopia since 2008.

\section{Exclusion criteria}

Studies with poor definition of the outcome of interest, the difficulty of extracting necessary data, and inability to get the necessary details from the author(s) were excluded.

\section{Outcomes of the study}

The study contained two objectives namely, the magnitude of prelacteal feeding practice and the effect of birthplace on prelacteal feeding practice in Ethiopia. The prevalence was computed by dividing the number of women/caregivers reported as giving solid, semisolid, or liquid food within 3 days of birth by the total number of participants (sample size) and multiplied by 100 . For the second objective, the odds ratio was computed by using the binary formula and it was estimated in the form of logs of the odds ratio.

\section{Data extraction}

The study was done from June, 03/2017 to September, $20 / 2017$. Following the quality appraisal of all relevant articles, the necessary data were extracted by two reviewers (WWTand DZA) and recorded on pre-prepared standardized Microsoft excel spreadsheet data extraction format. For each eligible study, data were extracted based on the following characters; author's first name, year of publication, sample size, number of study participants experienced the event, region, study setting, and the prevalence of prelacteal feeding practice. In addition to the above parameters, for the second objective, place of birth corresponding with experiencing status of the event (prelacteal feeding) was extracted.

\section{Data analysis}

Once the necessary data were extracted and recorded on the Microsoft spreadsheet, for prevalence studies, the prevalence, logarithm of the prevalence, and standard error of the logarithm of the prevalence was computed. For the factor, the event (prelacteal feeding) versus exposure (place of delivery) status was extracted. Then, the odds ratio, logarithm of the odds ratio, and the standard error of the logarithm of the odds ratio were calculated. All extracted data were exported to STATA/SE version 14 (Stata Corp LLC, Texas, USA) for further analysis.

The presence of heterogeneity among studies was checked visually using forest plot, and objectively, using the $\mathrm{I}^{2}$ statistical heterogeneity test. For both objectives, in the fixed-effect model, it has been observed that the $\mathrm{I}^{2}$ was greater than $>50 \%$. Thus, to determine the pooled estimates, the DerSimonian and Liard random-effect model was used [37]. To identify the influential study that caused variation, a sensitivity analysis was employed. Subgroup analysis was done by the region where primary studies were conducted, and by study setting. The existence of small studies publication bias was evaluated using the symmetry of funnel plots, and Egger's regression test [38].

\section{Results}

\section{Description of previous primary studies}

Initially, a total of 780 articles were collected, of which 689 from PubMed and the rest from other electronics search engines mainly Google Scholar, Google, and HINARI (Fig. 1).

In this study, a total of 18,828 study participants were included. The sample size of included studies ranged from 6761 in Amhara Region, and 333 in Afar region [39]. Six studies were included to show the effect of home delivery on the prelacteal feeding (Table 1). All the included studies were written in English and cross-sectional by design.

With regarding regional distribution, about $(45.8 \%)$ of the studies were conducted in Amhara region [26, 28, $29,40-47]$. The prevalence of prelacteal feeding practice ranged between 6.1\% [48], and 75.8\% [49] in South Nation Nationalities and Peoples (SNNPs) region and Oromia region, respectively. Concerning the distribution of studies, two of the studies were obtained from Tigray region [50, 51], a national report through EDHS [52], a study from Harari region [30], five from Oromia region $[25,49,53-55]$, two from SNNPs region [7, 48], and three studies from Afar region [39, 56, 57]. However, there were no studies from Benishangule Gumize region, Somali region, and Addis Ababa, the capital of Ethiopia.

\section{The association of home delivery with prelacteal feeding practice}

Regarding the association of place of birth and prelacteal feeding practice, six studies with a total of 3720 participants were included. Five studies, an institution based study from 


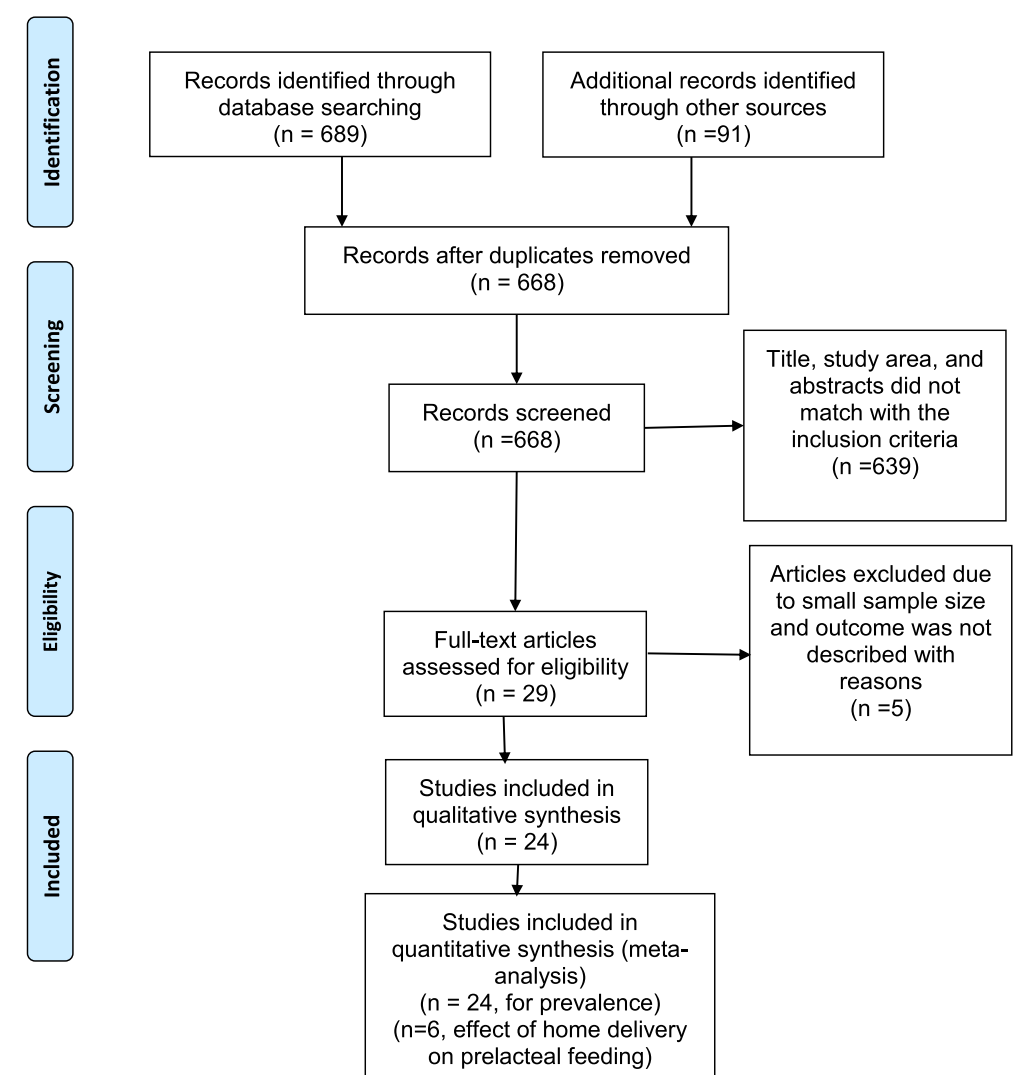

Fig. 1 PRISMA flow diagram indicating the study selection procedure to include into the systematic review and meta-analysis, Ethiopia, 2017

Harari region, Eastern Ethiopia [30], one national report [52], a community based study from Dabat Demographic and Health survey in Amhara Region [28], another a community based study from Amhara regiona [29], and a study from SNNPs of Ethiopia [7] reported that home delivery was positively associated with prelacteal feeding practice. On the other hand, a facility based study from northwest Ethiopia [47], and a community-based study from Amhara Region [45] showed that home delivery had no association with prelacteal feeding. The sample size of included studies ranged between 367, and 822 (Table 2). Except for a single study, all studies were published in reputable peer-reviewed journals.

\section{Pooled prevalence of prelacteal feeding practice}

The pooled prevalence of prelacteal feeding practice in Ethiopia was $26.95 \%$ (95\% CI: $17.76 \%, 36.14 \%)$. High heterogeneity was observed across the studies $\left(\mathrm{I}^{2}=99.6 \%, p<0.01\right)$ (Fig. 2). According to the sensitivity analysis, there was no single influential estimate that significantly accounted for it.

\section{Subgroup analyses}

\section{By geographical zones}

The subgroup analysis by the region where studies were done showed that the highest prevalence is observed in Afar region, Eastern Ethiopia 38.2\% (95\% CI: 23.8\%,
$52.6 \%)$ and the lowest prevalence in SNNPs of Ethiopia 13.9\% (95\% CI: 1.5, 29.37) (Fig. 3).

\section{By the study setting}

Subgroup analysis by study setting showed that the overall prevalence of prelacteal feeding practice among community-based studies to be $26.5 \%$ (16.8CI, 36.3\%) while for institution-based studies it was 31\% (95\% CI: I7.1\%, 55.7\%), and the observed difference was statistically significant $\left(\mathrm{I}^{2}=99.6 \%, p<0.01\right)$.

The funnel plot illustrated that there was symmetric distribution of studies (Fig. 4). Besides, the intercept (slop) of the Egger's test graph was not significantly deviating from the origin $(p=0.47)$ revealing the absence of publication bias (Bias $=3.38$; 95\% CI: 2.42, 4.34).

Association of the place of birth with prelacteal feeding practice In the random effect model, weight was allocated based on the sample size and the effect size. The maximum (21.32\%) and minimum (14.08\%) weight were given for Bekele $\mathrm{Y}$ et al., and Yenit $\mathrm{M}$ et al., respectively. In this model, it has been observed that there was a positive statistically significant correlation between home delivery and prelacteal feeding practice. As an illustration, the pooled odds of experiencing prelacteal 
Table 1 List of studies included to show the prevalence of prelacteal feeding practice among Ethiopian children, 2008-2017, a systematic review and meta-analysis, Ethiopia, 2017

\begin{tabular}{|c|c|c|c|c|c|}
\hline S.no. & Authors name & Study setting & sample size & Prevalence of prelacteal feeding & Study quality \\
\hline 1 & Tewabe T et al. 2016 [40] & Amhara & 423 & 19.4 & $88.8 \%$ \\
\hline 2 & Derso T et al. 2017 [41] & Amhara & 6761 & 56.1 & $100 \%$ \\
\hline 3 & Tilahun G et al. 2016 [42] & Amhara & 416 & 15.9 & $100 \%$ \\
\hline 4 & Gultie T et al. 2016 [26] & Amhara & 548 & 24.3 & $100 \%$ \\
\hline 5 & Liben L et al. 2016 [39] & Afar & 333 & 16.8 & $100 \%$ \\
\hline 6 & Egata G et al. 2013 [49] & Oromia & 860 & 75.8 & $88.8 \%$ \\
\hline 7 & Hailemariam TS et al. 2015 [25] & Oromia & 594 & 6.7 & $100 \%$ \\
\hline 8 & Lenja A et al. 2016 [48] & SNNP & 396 & 6.1 & $100 \%$ \\
\hline 9 & Mekuria G et al. 2015 [43] & Amhara & 423 & 74.0 & $100 \%$ \\
\hline 10 & Asemahagn et al. 2016 [44] & Amhara & 346 & 20.2 & $100 \%$ \\
\hline 11 & Bimirew D et al. 2016 [46] & Amhara & 739 & 11.9 & $88.8 \%$ \\
\hline 12 & Amare M et al. 2015 [7] & SNN & 485 & 21.9 & $100 \%$ \\
\hline 13 & Yenit M et al. 2017 [47] & Amhara & 367 & 19.1 & $100 \%$ \\
\hline 14 & Bililign N et al. 2016 [45] & Amhara & 782 & 11.1 & $88.8 \%$ \\
\hline 15 & Bekele Y et al. 2014 [30] & Harari & 634 & 43.8 & $88.8 \%$ \\
\hline 16 & Tariku A et al. 2016 [28] & Amhara & 822 & 26.8 & $100 \%$ \\
\hline 17 & Legese M et al. 2014 [29] & Amhara & 630 & 38.7 & $100 \%$ \\
\hline 18 & Teka B et al. 2015 [50] & Tigray & 530 & 12.8 & $88.8 \%$ \\
\hline 19 & Liben L et al. 2016 [56] & Afar & 337 & 49.6 & $100 \%$ \\
\hline 20 & Girma TS et al. 2008 [53] & Oromia & 650 & 11.8 & $100 \%$ \\
\hline 21 & Alemayehu Ay et al. 2015 [54] & Oromia & 371 & 9.7 & $88.8 \%$ \\
\hline 22 & Woldemichael B et al. 2016 [55] & Oromia & 373 & 14.7 & $100 \%$ \\
\hline 23 & Alemayehu M et al. 2014 [51] & Tigray & 418 & 17.2 & $100 \%$ \\
\hline 24 & Liben L et al. 2017 [57] & Afar & 615 & 42.9 & $88.8 \%$ \\
\hline
\end{tabular}

feeding among women who gave birth at home was increased by $5.16(95 \% \mathrm{CI}: 3.7,7.2)$ folds as compared to those who gave birth at health institutions. The $\mathrm{I}^{2}$ test suggested the presence of heterogeneity $\left(\mathrm{I}^{2}=\right.$ $60.3 \%, p=0.027$ ) (Fig. 5).

The sensitivity analysis of the six estimates also revealed that there was no any sign of influential effect size that affected the pooled estimate. According to the Egger's regression test, publication bias was not a concern $(p$-value $=0.097)($ Fig. 6).

\section{Discussion}

The result of this systematic review exhibited that the highest $(75.8 \%)$ prevalence of prelacteal feeding was observed in a study done in the year of 2011 in Oromia region [49], whereas the lowest (6.1\%) was from SNNPs in 2015 [48]. The discrepancy could be due to the study participants' educational status difference. The vast majority of study participants enrolled in Oromia's study were illiterate as compared to SNNPs of Ethiopia study. Previous studies showed that being illiterate increased the likelihood of

Table 2 List of studies included to examine the effect of home delivery on prelacteal feeding practice among Ethiopian Children, 2008-2017, a systematic review and meta-analysis, Ethiopia, 2017

\begin{tabular}{|c|c|c|c|c|c|}
\hline S.no. & Authors name & Region & Total sample size & Study setting & Study quality \\
\hline 1. & Amare M,et al. 2015 [7] & SNNPs $^{\mathrm{a}}$ & 485 & Community & $87.5 \%$ \\
\hline 2. & Yenit M et al. 2017 [47] & Amhara & 367 & Institutional & $100 \%$ \\
\hline 3. & Bililign N et al. 2016 [45] & Amhara & 782 & Institutional & $100 \%$ \\
\hline 4. & Bekele Y et al. 2014 [30] & Harari & 634 & Community & $87.5 \%$ \\
\hline 5. & Tariku A et al. 2016 [28] & Amhara & 822 & Community & $100 \%$ \\
\hline 6. & Legese et al. M2014 [29] & Amhara & 630 & Community & $100 \%$ \\
\hline
\end{tabular}

${ }^{a}$ SNNPs South Nation Nationalities, and Peoples 


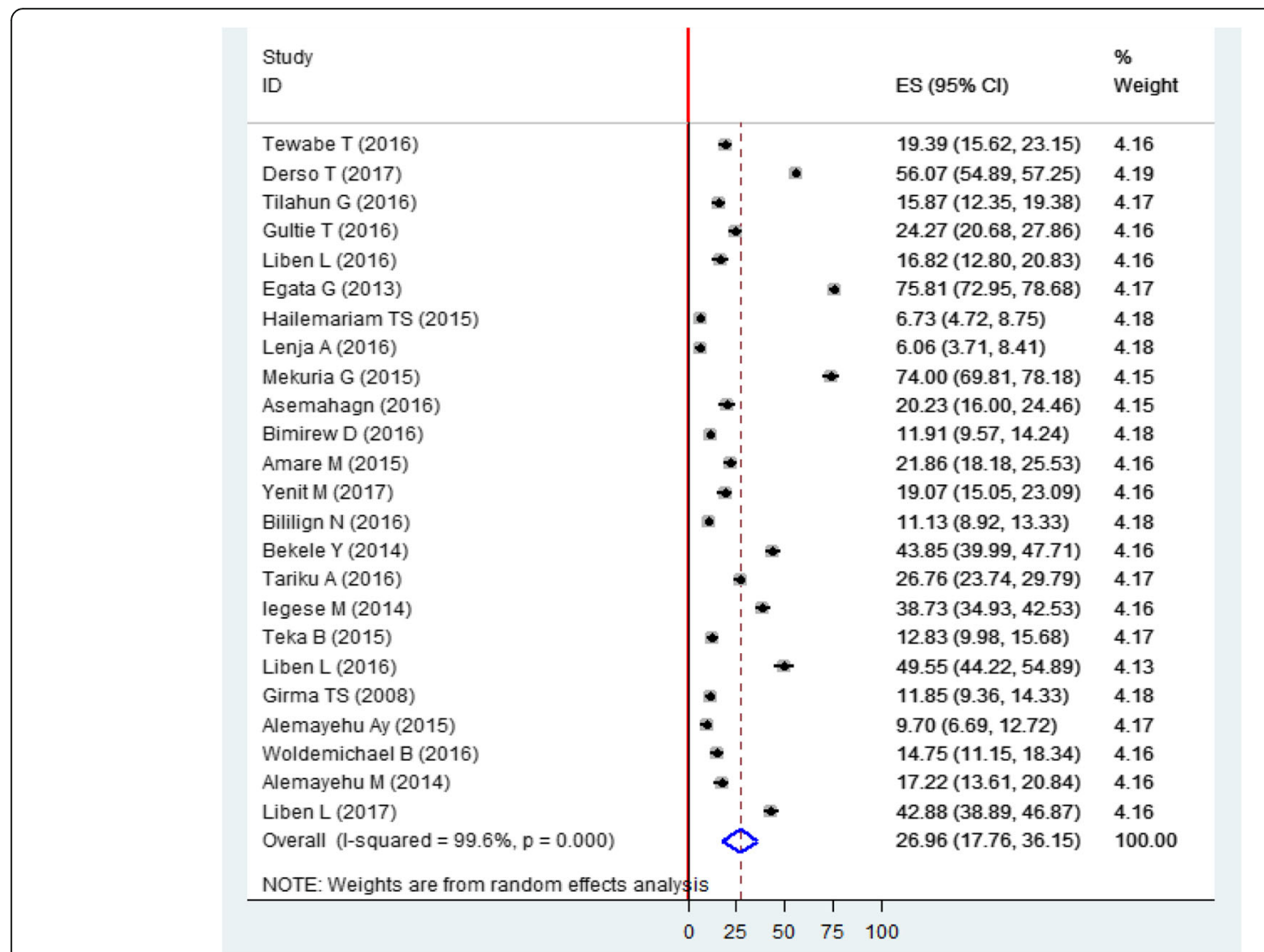

Fig. 2 Forest plot of the pooled prevalence of prelacteal feeding among Ethiopian children using the random effect model, a systematic review and eta-analysis, Ethiopia, 2017

practicing prelacteal feeding [48]. The time difference when the two studies conducted might be considered as the source of the variation. The expansion of Community Based Nutrition $(\mathrm{CBN})$ in the country level between this period may reduce the magnitude [58]. At the national level, the trend of prelacteal feeding has shown a decline from $27 \%$ in the year 2011 and $8 \%$ in 2016 [33].

The pooled prevalence of prelacteal feeding practice in Ethiopia to be $26.95 \%$ (95\% CI: $17.76 \%, 36.14 \%$ ). This implies that prelacteal feeding is a contributing malpractice factor which is interfering optimum breastfeeding in the country which needs strengthening of IYCF practice strategies. The likelihood of practicing prelacteal feeding among women who gave birth at home was five folds ( $\mathrm{AOR}=5.16,95 \% \mathrm{CI}: 3.7 \%, 7.2 \%)$ higher as compared to those women gave birth at Health facilities. This is suggesting that home delivery is not affecting only the health of women, rather it affects children's feeding practice.

The current finding is congruent with studies conducted in Nepal (26.5\%) [59], and a multilevel analysis study was done in twenty-two Sub-Saharan African countries including Ethiopia (32.2\%) [6].

However, this finding is higher than the EDHS 2016 report (8\%) [33] and twice higher than a survey done in
Timor-Leste(12.3\%) [60]. The EDHS report was publicized in 2016 while most of our primary studies were conducted in the years before 2016. Different IYCF interventions that were implemented by the Federal Minister of Health (FMOH) through the years could have helped in reducing prelacteal feeding over time [58]. The favorable traditional practice towards exclusive breastfeeding among Timorese mothers might contribute to reducing the magnitude [61]. The difference with Timor-Leste could be due to the fact that the study areas are located in a different segment of the world which could lead to differences in child feeding cultural practices.

The result of this study is far lower as compared to a nationwide study conducted in Vietnam in the year 2011 (73.3\%) [5]. Misconception towards breastfeeding and other social norms among Vietnamese mothers could attribute to high prelacteal feeding [5]. Furthermore, breastfeeding practices may explain this discrepancy; for instance, In the year 2011, exclusive breastfeeding was reported to be $52 \%$ in Ethiopia [62], while 20\% in Vietnam [63].

In the subgroup analysis, the burden of prelacteal feeding practice among regions was found to be different. The highest prevalence (38.24\%) was noted in the Afar region. Good ANC service utilization and institutional 


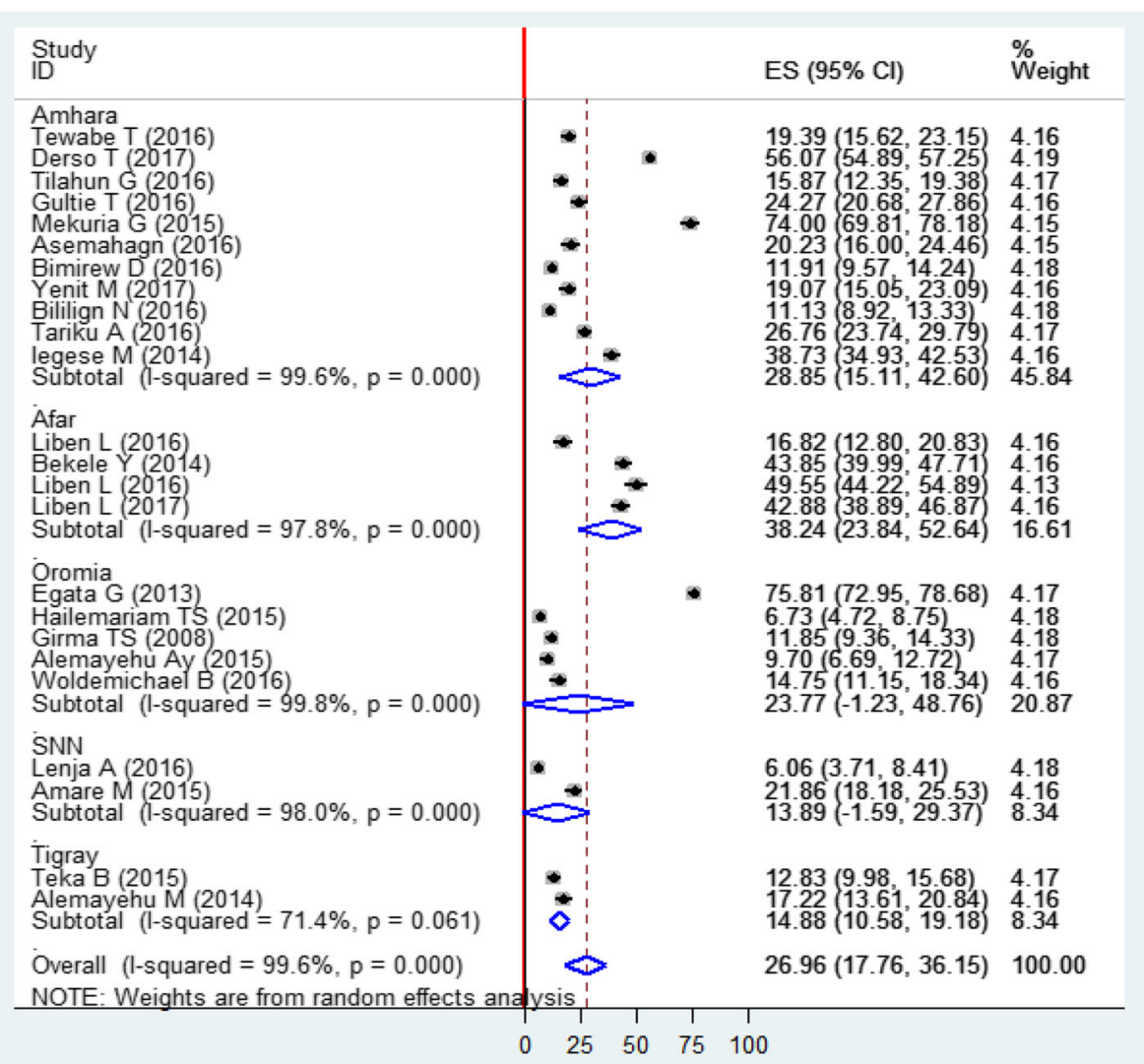

Fig. 3 Forest plot of subgroup analyses by regions among Ethiopian children using the random effect model, a systematic review and meta-analysis, Ethiopia, 2017

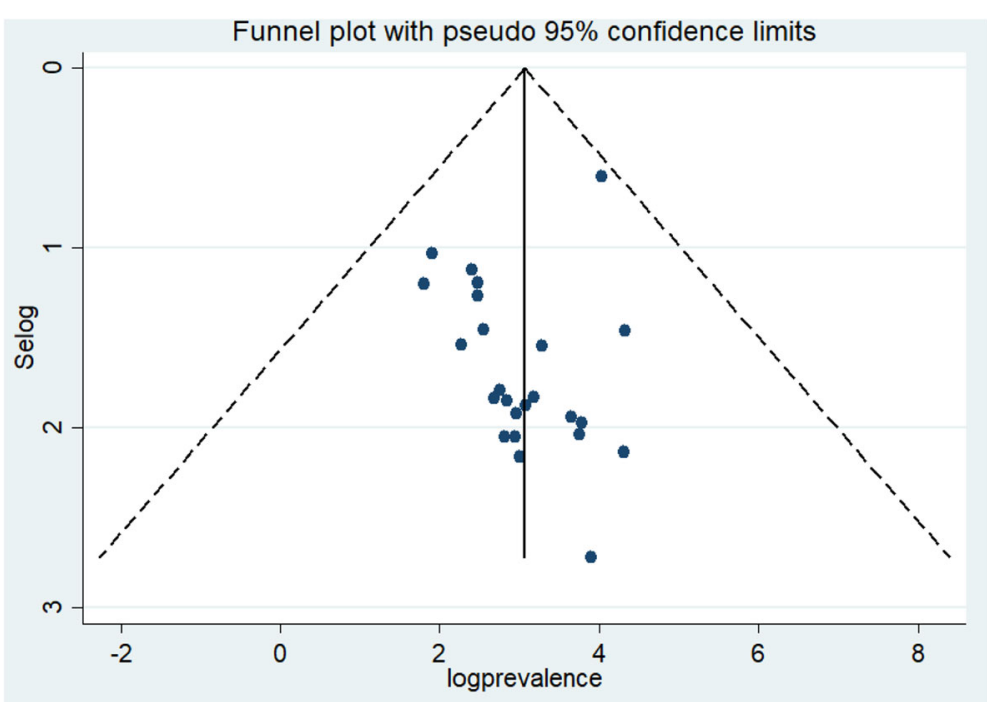

Fig. 4 Funnel plot showing publication bias of prevalence studies among Ethiopian children, a systematic review and meta-analysis, Ethiopia, 2017 


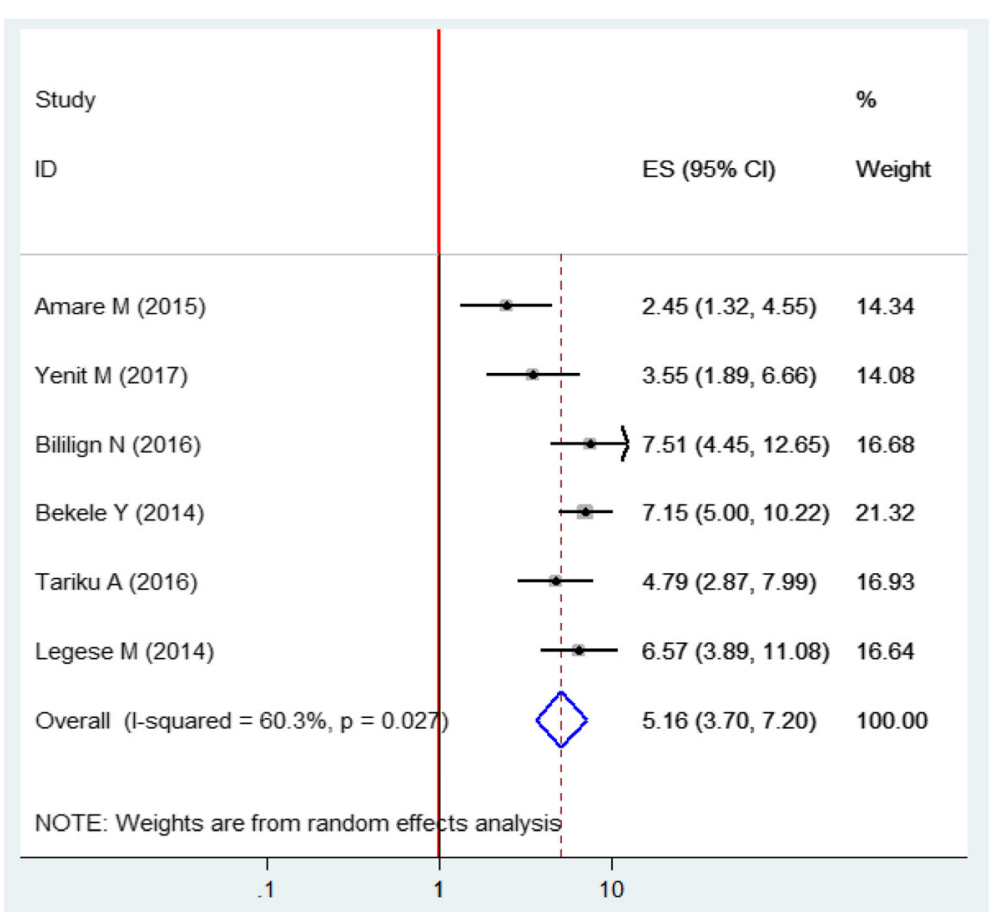

Fig. 5 Forest plot of the pooled estimate of the effect of home delivery on prelacteal feeding among Ethiopian children using the random effect model, a systematic review and meta-analysis, Ethiopia, 2017

delivery are factors which reduce prelacteal feeding. The lowest ANC and institutional delivery services in the region might describe the highest burden of prelacteal feeding [33]. During ANC visit mothers get advice about infant feeding and the importance of institutional delivery which further could improve infant feeding practices.
The finding of this study showed that home delivery practice was associated with prelacteal feeding. The pooled odds ratio of women who gave birth at their home was increased by five folds as compared to those who gave birth at health facilities. This finding is in agreement with a multilevel study in twenty-two Sub Saharan Africa including Ethiopia [6], and another multilevel study conducted in

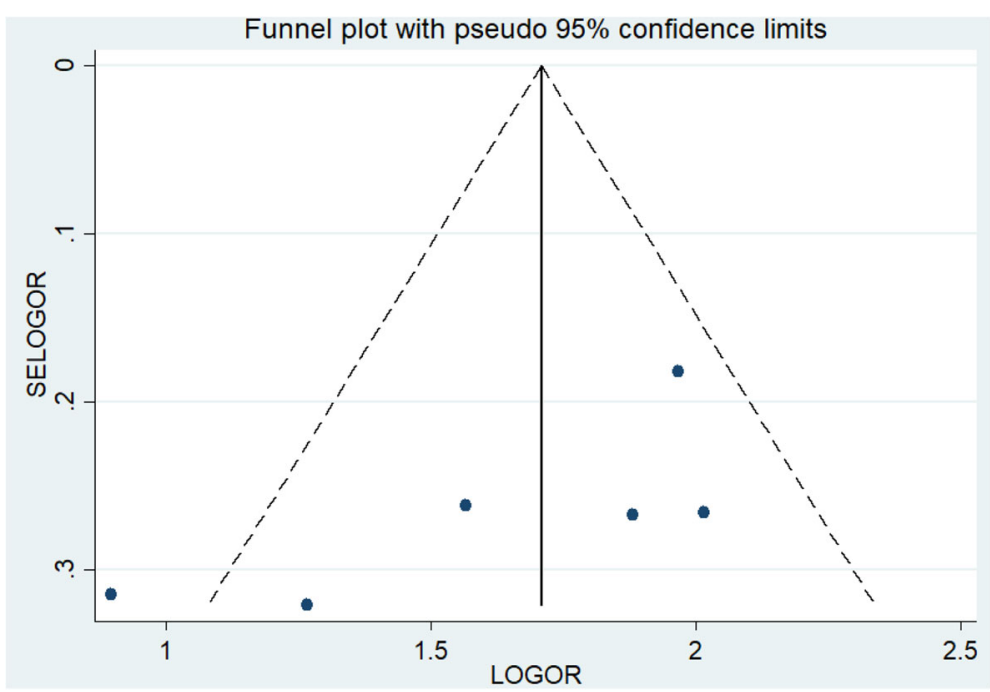

Fig. 6 A funnel plot showing publication bias of studies in the effect of home delivery on prelacteal feeding among Ethiopian children, a systematic review and meta-analysis, Ethiopia, 2017 
Ethiopia [24]. This is due to the fact that home delivery in Ethiopia is usually attended by traditional birth attendants who do not have the knowledge on the benefits of optimum breastfeeding and the harms following prelacteal feeding. On the other hand, Health facilities are places where early initiation of breastfeeding practice, the ill effects of early complementary feeding and ritual feeding practices are taught. At the same time, principles of IYCF practices, as well as the benefit of exclusive breastfeeding are sermonized by health professionals. This is supported by evidence from an Indian study that shows an increased prevalence of early initiation of breastfeeding and decreased the level of prelacteal feeding among mothers who gave birth at Health facilities than those who gave birth at home [64]. This review and meta-analysis study is the first of its kind in Ethiopia and searching key terms were broader which increased the number of included studies as a result, generalizability is possible with great confidence. Nevertheless, this study is not free of limitation. Accordingly, the study shared all the drawbacks of the random effect model. Because of lack of further subgroup definitions in the primary studies, the heterogeneity among studies couldn't be resolved. Moreover, it would have been very good if the study considered other maternal and institutional factors which influence the practice of prelacteal feeding.

\section{Conclusion}

Prelacteal feeding practice in Ethiopia was found to be high. The highest magnitude was observed in Afar region. Home delivery was found to be statistically correlated with prelacteal feeding practice. Therefore, advocating institutional delivery and creating awareness about optimal breastfeeding are strongly recommended. Moreover, special emphasis should be given in some regions where the problem is highly prevalent.

\section{Abbreviations}

EDHS: Ethiopian Demographic Health Survey; IYCF: Infant and Young Child Feeding; JBI: Joana Brig's Institute; NNP: National Nutrition Program; WHO: World Health Organization

\section{Acknowledgments}

The authors would like to thank Mr. Ashenafi Assmamaw and Mr. Animut Alebel for their unreserved support.

\section{Funding}

The study was funded by the University of Gondar. However, the funders have no role in the process of research work.

\section{Availability of data and materials}

All relevant data are available within the manuscript.

\section{Authors' contributions}

WWT and DTE conceived the research idea and prepared the review, appraise the quality of the articles, search articles, analyzed data and draft the manuscript. DZA, FWS, LDG, WGA, and AT participated in the search, quality appraisal, data analyses, and reviewing process of the manuscript. All authors have read and approved the final manuscript.
Ethics approval and consent to participate

Not applicable.

\section{Consent for publication}

Not applicable.

\section{Competing interests}

The authors declare that they have no competing interests.

\section{Publisher's Note}

Springer Nature remains neutral with regard to jurisdictional claims in published maps and institutional affiliations.

\section{Author details}

${ }^{1}$ Department of Community Health Nursing, School of Nursing, College of Medicine and Health Sciences, University of Gondar, Gondar, Ethiopia. ${ }^{2}$ Department of Human Nutrition, Institute of Public Health, College of Medicine and Health Sciences, University of Gondar, Gondar, Ethiopia. ${ }^{3}$ Department of Nursing, College of Medicine and Health Sciences, Debre Markos University, Debre Markos, Ethiopia. ${ }^{4}$ Department of Pediatrics and Child Health Nursing, School of Nursing, College of Medicine and Health Sciences, University of Gondar, Gondar, Ethiopia. ${ }^{5}$ Department of Psychiatry, School of Medicine, College of Medicine and Health Sciences, University of Gondar, Gondar, Ethiopia. ${ }^{6}$ Department of Epidemiology and Biostatistics, Institute of Public Health, College of Medicine and Health Sciences,

University of Gondar, Gondar, Ethiopia.

Received: 14 March 2018 Accepted: 20 August 2018

Published online: 22 October 2018

\section{References}

1. Khan MN, Islam MM. Effect of exclusive breastfeeding on selected adverse health and nutritional outcomes: a nationally representative study. BMC Public Health. 2017;17(1):889.

2. J.W: The economic benefits of breastfeeding: a review and analysis. Food and rural economics division, Economic Research Service, U.S. Department of Agriculture. Food assistance and nutrition research report no. 13. Washington dc; 2001. https://ageconsearch.umn.edu/record/33863/files/fa041903.pdf

3. Organization. WH: global strategy for infant and young child feeding. Geneva: World Health Organization; 2003. http://whqlibdoc.who.int/ publications/2003/9241562218.pdf

4. Ibadin OM, Ofili NA, Monday P, Nwajei CJ. Prelacteal feeding practices among lactating mothers in Benin City, Nigeria. Niger J Paediatr. 2013;40:139-44.

5. Nguyen PH, Keithly SC, Nguyen NT, Nguyen TT, Tran LM, Hajeebhoy N. Prelacteal feeding practices in Vietnam: challenges and associated factors. BMC Public Health. 2013:13(1):932.

6. Berde AS, Ozcebe H. Risk factors for prelacteal feeding in sub-Saharan Africa: a multilevel analysis of population data from twenty-two countries. Public Health Nutr. 2017:1-10.

7. Amare M: Assessement of prevalence of prelactal feeding and associated factors among mothers of children less than one year of age in mizanaman town benchmaji zone, south west ethiopia. 2015.

8. Chandrashekhar T, Joshi H, Binu V, Shankar P, Rana M, Ramachandran U. Breast-feeding initiation and determinants of exclusive breast-feeding-a questionnaire survey in an urban population of western Nepal. Public Health Nutr. 2007;10(2):192-7.

9. Lakati A, Makokha O, Binns C, Kombe Y. The effect of pre-lacteal feeding on full breastfeeding in Nairobi, Kenya. East Afr J Public Health. 2011;7(3):258-62.

10. El-Gilany A, Sarraf B, Al-Wehady A. Factors associated with timely initiation of breastfeeding in Al-Hassa province, Saudi Arabia. East Mediterr Health J. 2012;18(3):250.

11. Sharma IK, Byrne A. Early initiation of breastfeeding: a systematic literature review of factors and barriers in South Asia. Int Breastfeed J. 2016;11(1):17.

12. Smith ER, Locks LM, Manji KP, McDonald CM, Kupka R, Kisenge R, Aboud S, Fawzi WW, Duggan CP. Delayed breastfeeding initiation is associated with infant morbidity. J Pediatr. 2017;191:57-62. e52

13. Edmond KM, Zandoh C, Quigley MA, Amenga-Etego S, Owusu-Agyei S, Kirkwood BR. Delayed breastfeeding initiation increases risk of neonatal mortality. Pediatrics. 2006;117(3):e380-6. 
14. Mullany LC, Katz J, Li YM, Khatry SK, LeClerq SC, Darmstadt GL, Tielsch JM. Breast-feeding patterns, time to initiation, and mortality risk among newborns in southern Nepal. J Nutr. 2008;138(3):599-603.

15. Teshome B, Kogi-Makau W, Getahun Z, Taye G. T: magnitude and determinants of stunting in children under-five years of age in food surplus region of Ethiopia: the case of West Gojjam zone. Ethiop J Health Dev. 2009; 23:98-106.

16. Cooperative for Assistance and Relief Everywhere, Inc. (CARE). Infant and Young Child Feeding Practices: Collecting and Using Data: A Step-byStep Guide. 2010. http://nutritioncluster.net/wp-content/uploads/sites/4/2013/12/ final-iycf-guide-iycf-practices_eng.pdf

17. Sefene A, Birhanu D, Awoke W, Taye T. Determinants of exclusive breastfeeding practice among mothers of children age less than 6 month in Bahir Dar city administration, Northwest Ethiopia; a community based cross-sectional survey. Sci J Clin Med. 2013;2(6):153-9.

18. WHO: Global health risks: mortality and burden of disease attributable to selected major risks: World Health Organization; 2009. http://apps.who.int/ iris/handle/10665/44203

19. Arenz S, Rückerl R, Koletzko B, von Kries R. Breast-feeding and childhood obesity--a systematic review. Int J Obes. 2004;28(10):1247.

20. Hossain MM, Radwan MM, Arafa SA, Habib M, DuPont HL. Prelacteal infant feeding practices in rural Egypt. J Trop Pediatr. 1992;38(6):317-22.

21. Ogah A, Ajayi A, Akib S, Okolo S. A cross-sectional study of pre-lacteal feeding practice among women attending Kampala International University teaching hospital maternal and child health clinic, Bushenyi, Western Uganda. Asian J Med Sci. 2012;4(3):79-85.

22. Seid AM, Yesuf ME, Koye DN. Prevalence of exclusive breastfeeding practices and associated factors among mothers in Bahir Dar city, Northwest Ethiopia: a community based cross-sectional study. Int Breastfeed J. 2013;8(1):14.

23. Fentahun $\mathbf{W}$, Wubshet $M$, Tariku $A$. Undernutrition and associated factors among children aged 6-59 months in East Belesa District, Northwest Ethiopia: a community based cross-sectional study. BMC Public Health. 2016;16(1):506

24. Alemu ZA, Ahmed AA, Yalew AW, Birhanu BS, Zaitchik BF. Individual and community level factors with a significant role in determining child heightfor-age Z score in East Gojjam zone, Amhara Regional State, Ethiopia: a multilevel analysis. Arch Public Health. 2017;75:27.

25. Hailemariam TW, Adeba E, Sufa A. Predictors of early breastfeeding initiation among mothers of children under 24 months of age in rural part of West Ethiopia. BMC Public Health. 2015;15(1):1076.

26. Gultie T, Sebsibie G. Determinants of suboptimal breastfeeding practice in Debre Berhan town, Ethiopia: a cross sectional study. Int Breastfeed J. 2016;11:5.

27. Patel A, Banerjee A, Kaletwad A. Factors associated with prelacteal feeding and timely initiation of breastfeeding in hospital-delivered infants in India. J Hum Lact. 2013;29(4):572-8.

28. Tariku A, Biks GA, Wassie MM, Gebeyehu A, Getie AA. Factors associated with prelacteal feeding in the rural population of Northwest Ethiopia: a community cross-sectional study. Int Breastfeed J. 2016;11:14.

29. Legesse M, Demena M, Mesfin F, Haile D. Prelacteal feeding practices and associated factors among mothers of children aged less than 24 months in Raya Kobo district, north eastern Ethiopia: a cross-sectional study. Int Breastfeed J. 2014;9(1):189.

30. Bekele $Y$, Mengistie B, Mesfine F. Prelacteal feeding practice and associated factors among mothers attending immunization clinic in Harari region public health facilities, eastern Ethiopia. Open J Prev Med. 2014;4(07):529.

31. Fetene $\mathrm{N}$, Linnander E, Fekadu B, Alemu H, Omer H, Canavan M, Smith J, Berman P, Bradley E. The Ethiopian health extension program and variation in health systems performance: what matters? PLoS One. 2016;11(5): e0156438.

32. Kim SS, Rawat R, Mwangi EM, Tesfaye R, Abebe Y, Baker J, Frongillo EA, Ruel MT, Menon P. Exposure to large-scale social and behavior change communication interventions is associated with improvements in infant and young child feeding practices in Ethiopia. PLoS One. 2016;11(10):e0164800

33. ICF. CSACEa: Ethiopia Demographic and Health Survey 2016. Addis Ababa, Ethiopia, and Rockville, Maryland, USA: CSA and ICF; 2016.

34. Munn Z, Moola S, Lisy K, Riitano D, Tufanaru C. Methodological guidance for systematic reviews of observational epidemiological studies reporting prevalence and incidence data. Int J Evid Based Healthc. 2015;13(3):147-53.

35. Moola S, Munn Z, C T EA, K S RS, Currie M, Qureshi R, Mattis P, Lisy K, et al. Chapter 7: systematic reviews of etiology and risk. In: Aromataris E, Munn Z, editors. Joanna Briggs Institute Reviewer's Manual: The Joanna Briggs Institute; 2017.
36. Moher D, Liberati A, Tetzlaff J, Altman DG. The PRISMA Group (2009). Preferred Reporting Items for Systematic Reviews and Meta-Analyses: The PRISMA Statement. PLoS Med. 6(7):e1000097. https://doi.org/10.1371/journal. pmed1000097.

37. DerSimonian R, Laird N. Meta-analysis in clinical trials. Control Clin Trials. 1986;7(3):177-88. https://www.ncbi.n/m.nih.gov/pubmed/3802833

38. Egger M, Smith GD, Schneider M, Minder C. Bias in meta-analysis detected by a simple, graphical test. Bmj. 1997;315(7109):629-34.

39. Liben ML, Gemechu YB, Adugnew M, Asrade A, Adamie B, Gebremedin E, Melak Y. Factors associated with exclusive breastfeeding practices among mothers in dubti town, afar regional state, Northeast Ethiopia: a community based cross-sectional study. Int Breastfeed J. 2016;11(1):4.

40. Tewabe T. Timely initiation of breastfeeding and associated factors among mothers in Motta town, east Gojjam zone, Amhara regional state, Ethiopia, 2015: a cross-sectional study. BMC Pregnancy Childbirth. 2016;16(1):314

41. Derso T, Biks GA, Tariku A, Tebeje NB, Gizaw Z, Muchie KF, Shimeka A, Kebede $Y$, Abebe SM, Yitayal M, et al. Correlates of early neonatal feeding practice in Dabat HDSS site, Northwest Ethiopia. Int Breastfeed J. 2017;12:25.

42. Tilahun G, Degu G, Azale T, Tigabu A. Prevalence and associated factors of timely initiation of breastfeeding among mothers at Debre Berhan town, Ethiopia: a cross-sectional study. Int Breastfeed J. 2016;11:27.

43. Mekuria G, Edris M. Exclusive breastfeeding and associated factors among mothers in Debre Markos, Northwest Ethiopia: a cross-sectional study. Int Breastfeed J. 2015;10(1):1

44. Asemahagn MA. Determinants of exclusive breastfeeding practices among mothers in azezo district, Northwest Ethiopia. Int Breastfeed J. 2016;11:22.

45. Bililign N, Kumsa H, Mulugeta M, Sisay Y. Factors associated with prelacteal feeding in north eastern Ethiopia: a community based cross-sectional study. Int Breastfeed J. 2016;11:13.

46. Bimerew A, Teshome M, Kassa GM. Prevalence of timely breastfeeding initiation and associated factors in Dembecha district, North West Ethiopia: a cross-sectional study. Int Breastfeed J. 2016;11:28.

47. Yenit MK, Genetu H, Tariku A. Infant feeding counseling and knowledge are the key determinants of prelacteal feeding among HIV exposed infants attending public hospitals in Ethiopia. Arch Public Health. 2017;75:23.

48. Lenja A, Demissie T, Yohannes B, Yohannis M. Determinants of exclusive breastfeeding practice to infants aged less than six months in Offa district, southern Ethiopia: a cross-sectional study. Int Breastfeed J. 2016;11:32.

49. Egata $G$, Berhane $Y$, Worku A. Predictors of non-exclusive breastfeeding at 6 months among rural mothers in East Ethiopia: a community-based analytical cross-sectional study. Int Breastfeed J. 2013;8(1):8.

50. Teka B, Assefa H, Haileslassie K. Prevalence and determinant factors of exclusive breastfeeding practices among mothers in Enderta woreda, Tigray, North Ethiopia: a cross-sectional study. Int Breastfeed J. 2015;10(1):2.

51. Alemayehu M, Abreha K, Yebyo H, Zemichael K, Gebremichael H. Factors associated with timely initiation and exclusive breast feeding among mothers of Axum town, Northern Ethiopia. Sci J Public Health. 2014;2(5): 394-401.

52. Belachew $A B$, Kahsay $A B$, Abebe $Y G$. Individual and community-level factors associated with introduction of prelacteal feeding in Ethiopia. Arch Public Health. 2016;74:6

53. Girma T. Traditional newborn care in Jimma town, Southwest Ethiopia. Ethiopian J Health Sci. 2008;18(3)

54. Alemayehu AY, Tadele K: Knowledge and practice of mothers towards exclusive breastfeeding and its associated factors in Ambo Woreda West Shoa Zone Oromia Region, Ethiopia. https://pdfs.semanticscholar.org/76d2/ a0f162263f82b10ee1396e43b5320699e206.pdf

55. Woldemichael B, Kibie Y. Timely initiation of breastfeeding and its associated factors among mothers in Tiyo Woreda, Arsi zone, Ethiopia: a communitybased cross sectional study. Clinics Mother Child Health. 2016;13(221):2.

56. Liben ML, Abuhay T, Haile Y. The role of colostrum feeding on the nutritional status of preschool children in Afambo District, Northeast Ethiopia: descriptive cross sectional study. Eur J Clin Biomed Sci. 2016;2(6):87-91.

57. Liben ML, Wuneh AG, Zepro NB, Mulugeta A. Factors associated with prelacteal feeding in Afar Regional State, Northeastern Ethiopia: A Cross sectional study. 2016.

58. UNICEF: Guiding principles of community based Nutriton in Ethiopia. 2013. https://www.unicef.org/ethiopia/2014-12-15-NUTRITION-based.pdf

59. Khanal V, Adhikari M, Sauer K, Zhao Y. Factors associated with the introduction of prelacteal feeds in Nepal: findings from the Nepal demographic and health survey 2011. Int Breastfeed J. 2013;8(1):9. 
60. Rajendra Karkee M, Dharan N, Lee AH: Prelacteal feeding of newborns in post-conflict Timor-Leste. 2016.

61. Leste MoHTLT: National Nutrition Strategy. Dili, Timor-Leste: Ministry of Health Timor Leste; 2004. https://extranet.who.int/nutrition/gina/sites/ default/files/TLS\%202014\%20National\%20Nutrition\%20Strategy.pdf

62. International. ECSAal: 2011 Ethiopia Demographic and Health Survey: Key Findings. Calverton, Maryland: CSA and ICF International; 2012.

63. NIN AT, UNICEF: nutrition surveillance. Hanoi, Vietnam: National Institute of nutrition; 2011. Vietnam Nutrition profile 2010. https://www.unicef.org/ vietnam/media_18458.html

64. Jain A, Baliga BS, Rao S, Shankar MV, Srikanth B: Does institutional delivery help in improving infant and child health care practices and health promotion related parameters? A study from Bellary, Karnataka. In: BMC Proceedings: 2012: BioMed Central; 2012: O22.

Ready to submit your research? Choose BMC and benefit from:

- fast, convenient online submission

- thorough peer review by experienced researchers in your field

- rapid publication on acceptance

- support for research data, including large and complex data types

- gold Open Access which fosters wider collaboration and increased citations

- maximum visibility for your research: over $100 \mathrm{M}$ website views per year

At BMC, research is always in progress.

Learn more biomedcentral.com/submissions 